\title{
Profilaxis de las infecciones urinarias
}

\author{
JOSE FERELES CASTELI_ \\ Jefe del Servicio de Medicina Preventiva \\ I Iospital Clínico San Carlos. Universidad Complutense de Madrid
}

\section{INTRODUCCIÓN}

Las infecciones urinarias en medio hospitalario o nosocomial constituyen la causa más importante de infección adquirida en nuestro medio y, probablemente, el origen más frecuente de sepsis por Gram negativos. El catéter vesical permanente se implanta en más del $10-12 \%$ de todos los enfermos ingresados, independientemente de su patología de base. Por estos motivos debe centrarse nuestra aportación en esta Monografía sobre Infecciones urinarias, cn lo que podría llamarse: Infección urinaria adquirida en medio hospitalario; El papel del catéter vesical permanente; Medidas de Control y Prevención.

Según los diferentes estudios EPINE realizados en España, y acumulados de 1990-1994, se sabe que un 7.1-8.5\% de los enfermos ingresados en los hospitales del estudio padecían una infección hospitalaria. Si las cifras se centran en un núcleo permanente de 74 hospitales participantes, entonces la prevalencia de infección nosocomial se extiende de un $8,9 \%$ a un $7,6 \%$ de los pacientes ingresados. De todos los pacientes infectados el 2,9-2,1\% tenían localización urinaria de la infección, tasa por encima de la infección quirúrgica, respiratoria y bacteriemia.

En el l lospital Clínico San Carlos, después de muchos años de experienciá, nucstras tasas de prevalencia de infección nosocomial y de pacientes infectados se encuentran entorno al $11 \%$ y $9 \%$ respectivamente, siendo las infecciones más frecuentes las urinarias ( $25 \%$ ), seguidas de las post-quirúrgicas, respiratorias $\mathrm{y}$ bacteriemias.

I a primera conclusión a la que podría llegarse es que las infecciones nosocomiales constituyen una patología importante cn los hospitales (hasta un 
$9 \%$ de los enformos ingresados las padecen) y que dentro de ellas las infecciones urinarias son las más frecuentes.

Existe numerosa literatura sobre la trascendencia médiea social y económica de las infeciones hospitalarias en la gue no podemos entrav en esta ocasión. Sin embargo de todos los estudios publicados. se desprende cue las infecciones uinarias son las más frecuentes de las infeciones nosocomiales, tienen carácler endémico y sutonen un enorme coste en días de estancia adicionales, consumo de agentes antimicrobianos y complicaciones, algunas de ellas muy graves.

Según el tipo de estudio epidemiologico realizado - sistema de vigilancia por incidencia, prevalencia, prospectivo, retrospectivo etc...-las infecciones uninarias pueden alcanzar desde un 25\% al $74 \%$ de todas las infecciones adquindas en el hospital, si se incluyen los casos de bacteriuria asintomática. En hospitales terciarios y en centros de larga cslancia d problema es aún mayor. I Iasta un $80 \%$ de las infecciones urinarias aparecen en pacientes sondados, ya que ef catéter de balón constituye el factor de riesgo más importante en uste tipo de infecciones.

Los agentes causales de las infecciones urinarias son fundamentalmente las Enterobacteriaceas, y particularmente E. Coli. Enterobacter, Proteus mirábilis, Klebsiclla y Serratia. Estos microorganismos junto con la Pscudomona aeruginosa, constituyen más del $80 \%$ de los agentes etiológicos. De todos modos cualquier microorganismo patógeno puede considerarse agente causal de infección urinaria en uno de estos pacientes.

\section{EL PAPEL DEL CATÉTER VESICAI PERMANENTE}

Como decimos, un $75-80 \%$ de los sondajes vesieales se siguen de bacteriuria y el $5 \%$ restante de otros procedimientos de instrumentación urologica. Según Burke y otros existen dos tipos de fadores de riesgo en la génesis de la infección urinaria nosocomial.

El primer grupo de factores se llama de tipo einalterables y comprende el scxo femenino, la edad avanzada y el grado de debilitación del paciente. I tos factores walterablesw (o aquellos sobre los que se puede influir) son: la indicación del cateterismo, la duración del mismo, la agrupación de los enfermos con sonda, la téenica de sistema cerrado y estéril de recogida de orina y tipo de sistema de drenaje.

Todos los factores mencionados influyen — de un modo más o menos esencial-- en la patogénesis de la infeción urinaria cn el paciente con catcterismo vesical permanente.

Los micoorganismos patógenos entran en el sistema y vias urinarias a tarvés de varias vías. En primer lugar en el momento del cateterismo, iniroduciendo micoorganismos de la uretra a la vejiga. En segundo lugar, pueden lle- 
gar a la vejiga a partir de la fina pelicula que se forma alrededor del catéter y en la zona de contacto catéter-mucosa vesical. En tercer lugar a través de la luz de la sonda una vez que el sistema de drenaje se ha contaminado. Este último es el mecanismo más frecuente como pucrta de cntrada y se produce por desconexión del catéter del sistema cerrado, por inyccciones o lavados intraIuminales, por las manos contaminadas del personal que atiende a otros enfermos sondados, antisépticos colonizados y otros procedimientos de mala práctica médica y do enfermería. El catéter permanente destruye asimismo la mucosa protectora de la vejiga, causa daño al uroendotelio y pucde producir un decúbilo con reacción inflamatoria local posterior. Existen estudios que demucstran la existencia de factores especificos de virulencia de microorganismos que inducen reacciones locales y que facilitan la infección urinaria. Según Kunin, con una experiencia considerable en el tema, las bacterias pueden tener acceso a la vejiga por los siguientes mecanismos:

1. Preparación inadecuada del área pcriuretral antes de la inserción del catćter.

2. Mala asepsia en la técnica del cateterismo.

3. Traumatismo uretral o necrosis por presión en el meato por utilización de una sonda demasiado grande.

4. Entrada de bacterias cn la unión entre el catéter y cl meato o seno urinario. Este cfecto es particularmente problematico en mujeres.

5. Contaminación en la concxión entre el catéter y el tubo o línea de recogida, debido a desconexión o irrigación innecesaria.

6. Contaminación del sistema de recogida, con flujo retrógrado hacia la vejiga (esto se elimina con un buen sistema de drenaje cerrado).

Numerosos estudios demuestran que existen grandes posibilidades de eliminar o reducir estos factores de riesgo, de los cuales el más importante es el abuso que se hace del catéter vesical permanente, y que cstá directamente incorporado a la atención y cuidados de enfermería del medio hospitalaria.

\section{MEDIDAS DE CONTROL Y PREVENCION}

En tanto se aclaran una seric de mecanismos patogénicos implicados en la infección urinaria, las únicas medidas de control y prevención de la infección deben basarse cn la indicación y los cuidados del cnfermo con catéter vesical permanente.

Para ello hay que reconsidkrar una seric do medidas que impidan o dismifuyan las posibilidades de entrada de microorganismos en el sistema ccrrado y cstéril de recogida de orina y que sean eficaces durante un periodo de 7-10 días. 
Un sistema cerrado y estéril de recogida de orina es aquel que no se permite desconexiones entre la sonda y cl colcctor, y cl vaciamiento de la orina se realiza de modo que no penetre aire en el interior de bas líneas de conducción.

Este sistema debe generalizarse en todos los enfermos con catéter permanente y que no necesitan desconexiones frecuentes.

Las indicaciones del catéter permanente deben revisarse a la baja, evitando su uso siempre que se pueda.

Las medidas alternativas son el condón en cl hombre, el drenaje suprapúbico $y$, cn todo caso, el cateterismo intermitente. Debe, pués, restringirse el uso del catéter permancnte y la duración del cateterismo.

La técnica aséptica de sondaje urinario debe ser obligatorja. La antisepsia previa del enfermo, la utilización de guantes, mascarilla, paños estériles etc. es imprescindible. La colocación posterior de un sistema corrado y estéril de recogida de orina ya ha sido mencionada como medida de eficacia comprobada.

En los enfermos cateterizados, la limpieza y lavado perineal y pericatéter es imprescindible, asi como en la unión catêter-meato que deberá lavarse una o dos veces al día con aguá y jabón.

El sistema de recogida de orina, debe vaciarse regularmente y ser colgado a nivel inferior al de la vejiga, sustituyéndose los catéteres únicamente cuando funcionan med o están contaminados.

No se ha demostrado la eficacia de medidas tales como irrigación del sistema con antisépticos, antibióticos o aporte de líquidos por via oral.

FI uso profiláctico de antimicrobianos no se recomicnda en enfermos cateterizados durante largo tiempo.

Como dice el mismo Kunin, cl catéter vesical es un hecho en la práctica médica. Es un instrumento muy vádido cuando se usa por una indicación correcta y se emplea con técnica aséptica.

Cuando se usa inadecuadamente, es la fucnte más importante de infección nosocomial grave por Gram negativos.

\section{BIBILIOGRAFLA}

1. Prevalencia de las Infecciones Nosucomiales en los Hospilales Españoles. Proyecto EPINE, Soc. Esp. Figiene y Me Preventiva I Iospit. Edit. 1945.

2. Bikke. J. P.; Gakimald R. A. y cols., Yorke Merlical Books, 1981.Pags 95-98

3. KIxiN C. M., Lea and Febiger, Edit, 1972.

4. Vi:LA R. y AJ fis J. M., Salvat, Edit, 1982. 